\title{
PANORAMA DOS PRESOS FEDERAIS ASSISTIDOS PELA DEFENSORIA PÚBLICA DA UNIÁO NO RIO DE JANEIRO
}

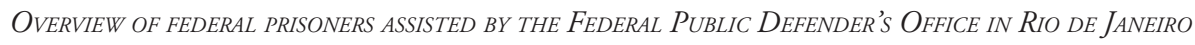

Letícia Sjöman Torrano Defensora Pública Federal. Coordenadora do Núcleo Criminal da DPU/RJ

Carolina Soares Castelliano Lucena de Castro Doutoranda em Teorias Juridicas Contemporâneas na Universidade Federal do Rio de Janeiro. Defensora Pública Federal

\author{
Ethel Proença Braga \\ Mestre em Politicas Públicas em Direitos Humanos - NEPP-DH/UFRJ \\ Assistente Social do Núcleo Criminal da DPU/RJ \\ Amanda Fonseca Leite Pangaio \\ Graduada em Serviço Social pela UFRJ \\ Marco Antonio da Silva Santos \\ Graduado em Serviço Social pela UNIRIO \\ Valdylane Assis de Oliveira \\ Graduada em Serviço Social pela UFRJ
}

\section{INTRODUÇÁO}

Esta é a segunda edição do Panorama dos Presos Federais assistidos pela Defensoria Pública da União no Rio de Janeiro (DPU/RJ), em continuidade à ação que visa traçar o perfil das pessoas em situação de privação de liberdade.

Estratégia essa fundamental para o atendimento das demandas desse segmento populacional, que transcende à prestação de assistência jurídica, mas que caminha na direção da defesa de direitos, em consonância com a missão institucional.

A Coordenação do Núcleo Criminal da DPU/RJ realizou a construção do II Panorama a partir da compilação e sistematização de dados relativos aos presos federais assistidos pela Defensoria Pública da União, que se encontram, ou já estiveram, custodiados em estabelecimentos prisionais existentes na cidade do Rio de Janeiro no referido período, tendo por base de dados os atendimentos prisionais realizados entre outubro de 2015 a setembro 
de 2017 e as informações coletadas em processos judiciais e de assistência jurídica.

Importante esclarecer que os atendimentos prisionais realizados pelo Núcleo Criminal da DPU/RJ têm como objetivo a prestação de informaçóes processuais, a coleta de informaçóes diretamente dos presos para desenvolvimento de defesa técnica, bem como o recebimento de demandas relativas ao acesso a bens e serviços inerentes a sua condiçáo humana, dentro da perspectiva de garantia de direitos, e consequente encaminhamento das mesmas.

O II Panorama dos Presos Federais Assistidos pela Defensoria Pública da União no Rio de Janeiro ampliou os indicadores sociais a serem analisados incluindo informaçóes sobre escolaridade, condição de saúde, situaçáo laboral, pedido de refúgio, e a sentença exarada pela Justiça Federal.

O documento está dividido em tópicos temáticos, que visam a melhor compreensão e análise dos dados e estatísticas apresentadas. Assim, na primeira parte, procurou-se esclarecer a forma como os presos federais, assistidos pela DPU/RJ, no período compreendido entre outubro de 2015 e setembro de 2017 estão distribuídos pelo sistema prisional na cidade do Rio de Janeiro.

Posteriormente, são realizadas análises de alguns aspectos e características relacionadas aos presos federais assistidos pela DPU/RJ. Começaremos pela verificação da distribuição geográfica - por Unidade Prisional, por país/continente e solicitação de refúgio dos estrangeiros; perfil do preso federal do Rio de Janeiro - que conta como indicadores a nacionalidade, o sexo, a faixa etária, a escolaridade, o estado civil e a prole; atividade laboral, condiçáo de saúde e processo judicial - desmembrado em tipificação e sentença, havendo análise da interligação e cruzamento entre esses dados.

Diante do papel constitucional a ser desempenhado pela Defensoria Pública da União, o presente Panorama, em sua segunda edição, pretende traçar uma radiografia do contingente de pessoas encarceradas assistidas pela Defensoria Pública da União, interligada ao I Panorama, a fim de auxiliar na melhor prestação de assistência jurídica integral e gratuita, bem como na promoçáo e defesa dos direitos humanos dessa parcela de pessoas estigmatizada e vulnerável.

Não há dúvida de que o II Panorama tem o potencial de contribuir para o desenvolvimento e aperfeiçoamento das políticas institucionais por parte da Defensoria Pública da União, como também para servir de subsídio para a avaliação da efetividade de políticas públicas implementadas no sistema penitenciário, de responsabilidade dos órgáos e instituiçóes competentes, além de auxiliar na própria prestação jurisdicional em relação ao preso federal. 


\section{Distribuiçáo dos presos federais assistidos pela Defensoria Pública da Uniáo na cidade do Rio de Janeiro}

O total de presos federais assistidos pelo Núcleo Criminal da DPU/RJ durante o período compreendido entre outubro de 2015 a setembro de 2017, foi de 135 pessoas.

Salienta-se que os réus ou indiciados presos em decorrência de inquéritos/processos de competência da Justiça Federal do Rio de Janeiro são custodiados em estabelecimentos estaduais, distribuídos pela cidade do Rio de Janeiro.

Incluem-se nesse trabalho as pessoas presas em decorrência de processos de extradição em trâmite no Superior Tribunal Federal, que se encontram custodiadas nos estabelecimentos prisionais existentes na cidade do Rio de Janeiro.

A grande maioria dos presos federais do sexo masculino é custodiado no Presídio Ary Franco, localizado em Agua Santa, enquanto as do sexo feminino, por sua vez, no presídio Joaquim Ferreira, localizado no Complexo de Gericinó.

A distribuição dos presos federais, assistidos pela Defensoria Pública da União/RJ, pode ser melhor visualizada, através da Tabela 1 e do Gráfico 1.

Tabela 1: Distribuiçáo de assistidos presos nas Unidades prisionais da cidade do Rio de Janeiro

\begin{tabular}{|l|l|c|}
\hline Unidades Prisionais & Localização (Bairro) & $\begin{array}{l}\text { Quantitativo de Presos } \\
\text { Federais Assistidos pela } \\
\text { DPU/RJ }\end{array}$ \\
\hline Presídio Ary Franco & Água Santa & 105 \\
\hline $\begin{array}{l}\text { Cadeia Pública Joaquim Ferreira } \\
\text { de Souza }\end{array}$ & Bangu & 20 \\
\hline Penitenciária Dr. Serrano Neves & Bangu & 1 \\
\hline $\begin{array}{l}\text { Penitenciária Laércio da Costa } \\
\text { Pelegrino }\end{array}$ & Bangu & 1 \\
\hline Instituto Penal Vicente Piragibe & Bangu & 1 \\
\hline Presídio Elizabeth Sá Rego & Bangu & 1 \\
\hline Presídio Evaristo de Moraes & Sáo Cristóvão & 1 \\
\hline Penitenciária Milton Dias Moreira & Japeri & 2 \\
\hline Presídio João Carlos da Silva & Japeri & 1 \\
\hline $\begin{array}{l}\text { Cadeia Pública Juíza de Direito } \\
\text { Patricia Acioli }\end{array}$ & São Gonçalo & 135 \\
\hline Cadeia Pública Romeiro Neto & Magé & 1 \\
\hline Total & & \\
\hline
\end{tabular}


Gráfico 1: Distribuiçáo de assistidos presos nas Unidades prisionais da cidade do Rio de Janeiro

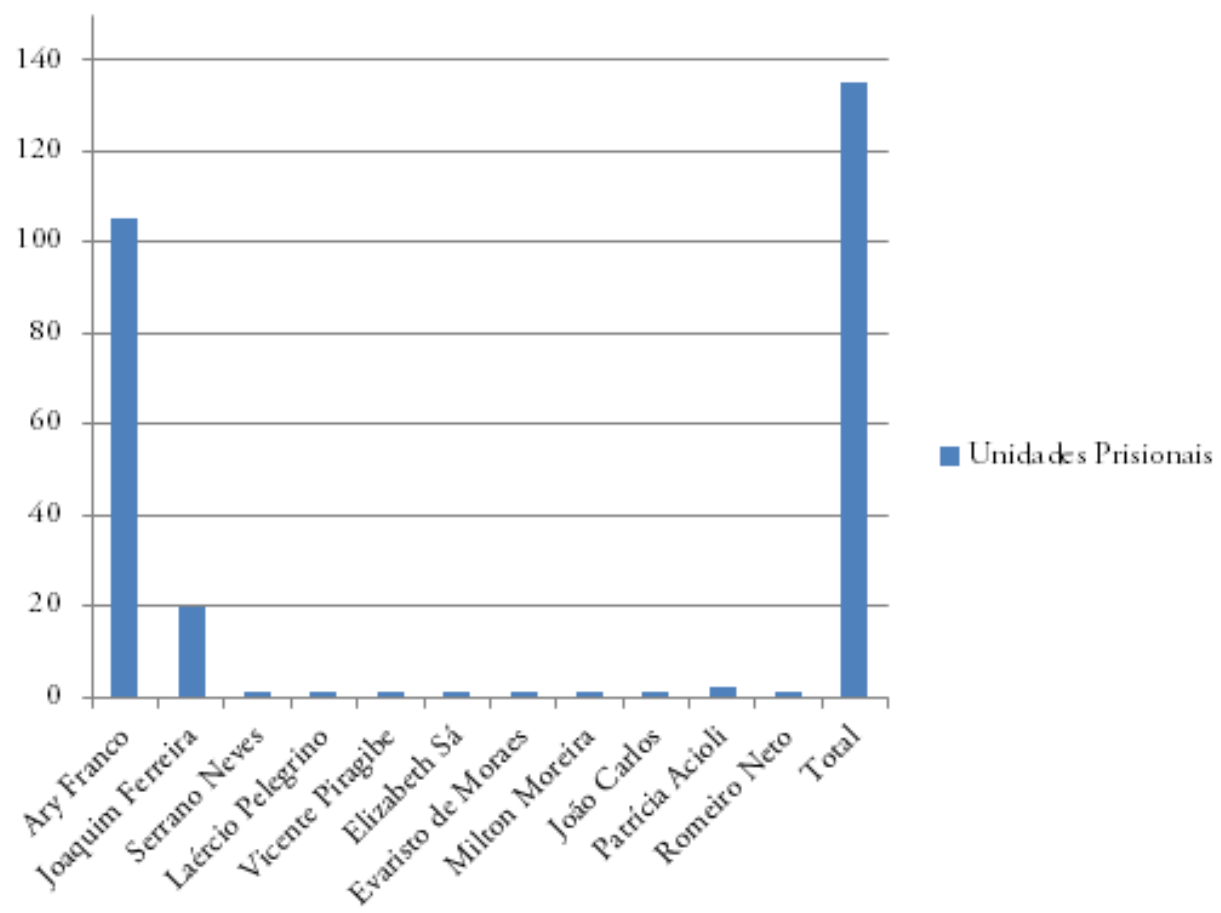

\section{Distribuição Geográfica}

Verificou-se que dentre os 135 presos federais do referido período, 51 presos são estrangeiros, sendo que esses assistidos estáo distribuídos em seis unidades do sistema prisional do Rio de Janeiro, da seguinte forma: quanto às internas do sexo feminino, 08 encontravam-se acauteladas na Cadeia Pública Joaquim Ferreira de Souza. Em relação aos internos do sexo masculino, 43 encontravam-se custodiados no Presídio Ary Franco

Dentre os presos estrangeiros assistidos pela DPU/RJ, foram identificadas 25 nacionalidades diferentes, 1 caso de estrangeiro apátrida e 1 caso de dupla nacionalidade, conforme distribuição da Tabela 2 e Mapa 1. 
Tabela 2: Verificação das nacionalidades dos Presos Estrangeiros

\begin{tabular}{|l|l|l|l|l|l|l|l|l|}
\hline \multicolumn{2}{|l}{ Europa } & \multicolumn{2}{l}{ Ásia } & \multicolumn{2}{l|}{ África } & \multicolumn{2}{l|}{ Árica } \\
\hline Bulgária & 1 & Turquia & 1 & Gana & 2 & EUA & 1 \\
\hline Hungria & 1 & Vietná & 1 & Senegal & 2 & Colombia & 3 \\
\hline Portugual & 2 & - & - & Nigéria & 3 & Argentina & 4 \\
\hline Espanha & 4 & - & - & Angola & 5 & Paraguai & 2 \\
\hline Suécia & 1 & - & - & - & - & Peru & 1 \\
\hline Alemanha & 2 & - & - & - & - & Venezuela & 2 \\
\hline França & 1 & - & - & - & - & Jamaica & 1 \\
\hline Itália & 4 & - & - & - & - & Bolívia & 1 \\
\hline Lituânia & 1 & - & - & - & - & - & - \\
\hline Ucrânia & 2 & - & - & - & - & - & - \\
\hline Rússia & 2 & - & - & - & - & - & - \\
\hline $\begin{array}{l}\text { Total/ } \\
\text { Continente: }\end{array}$ & $\mathbf{2 1}$ & $\begin{array}{l}\text { Total/ } \\
\text { Continente: }\end{array}$ & $\mathbf{2}$ & $\begin{array}{l}\text { Total/ } \\
\text { Continente: }\end{array}$ & $\mathbf{1 2}$ & $\begin{array}{l}\text { Total/ } \\
\text { Continente: }\end{array}$ & $\mathbf{1 5}$ \\
\hline
\end{tabular}

\section{Mapa 1: Demonstração no Mapa dos Continentes da distribuiçáo Geográfica}

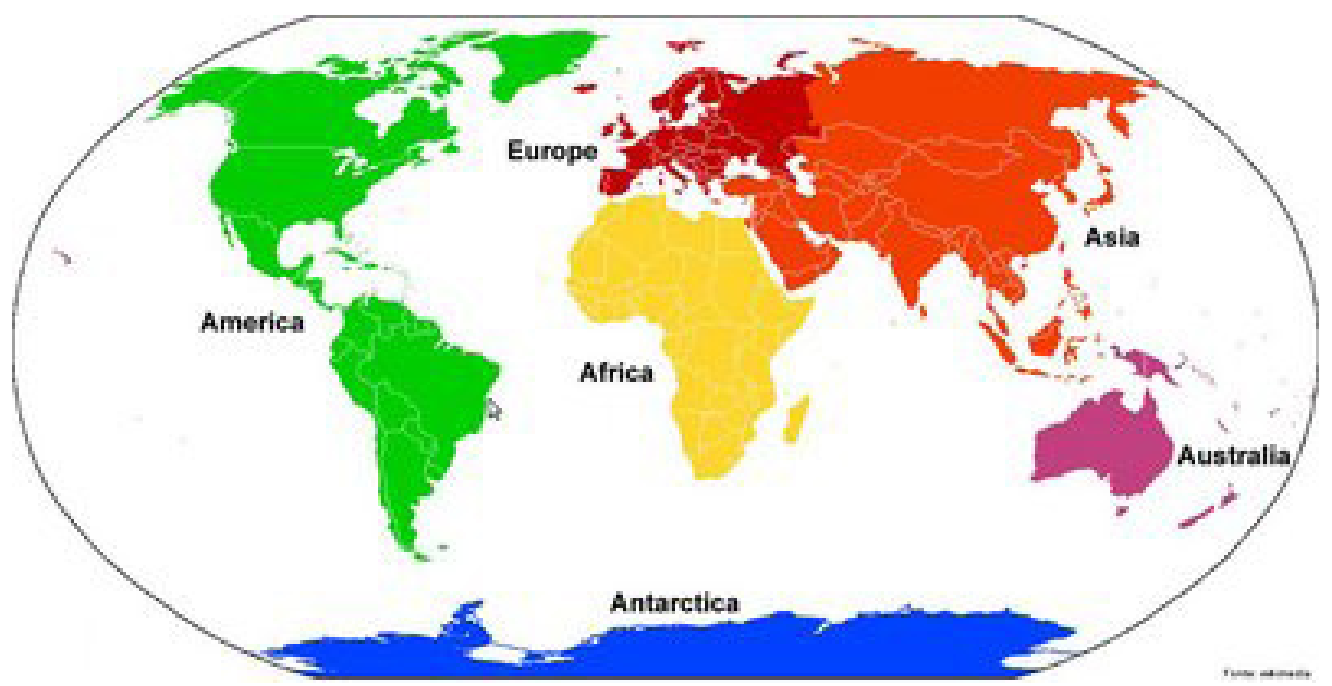

É possível verificar, dessa forma, que no período avaliado, a quantidade de estrangeiros provenientes do continente europeu e do continente americano foi superior aos da Âfrica e da Ásia. 
Pela análise dos países de origem dos presos estrangeiros assistidos pelo Núcleo Criminal da Defensoria Pública da União no Rio de Janeiro, é possível concluir que a situação dos mesmos guarda sensíveis particularidades em relação aos demais presos federais brasileiros, uma vez que a grande maioria provém de países que náo falam a língua portuguesa e que possuem cultura, valores e hábitos distintos de nossa sociedade.

Circunstância que é agravada pela ausência da rede de proteção familiar próxima, perspectiva que compromete a preservação dos vínculos afetivos parentais e comunitários enquanto perdure a situação de privação de liberdade.

Cabe ressaltar que alguns países não possuem representação consular no Estado do Rio de Janeiro, fato que intensifica a vulnerabilidade desses presos junto ao Sistema de Justiça Criminal.

\subsection{Estrangeiros que solicitaram refúgio ao Brasil}

Dos 51 presos estrangeiros que tiveram suas defesas patrocinadas pela DPU/RJ, 10 solicitaram refúgio ao Brasil, representando um percentual de aproximadamente $20 \%$ desses assistidos.

\section{Gráfico 2: Solicitação de refúgio}

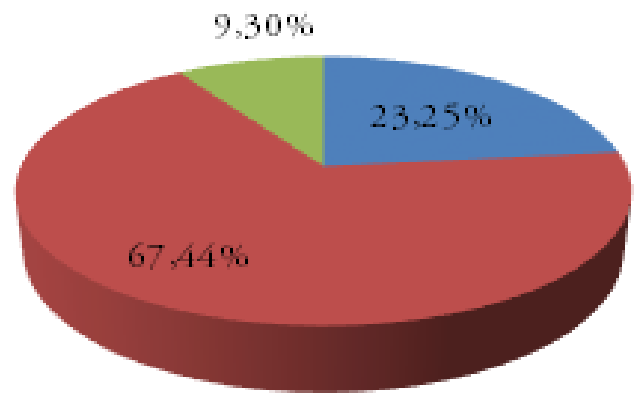

Solicit ou

Não solicitou

Não declara do 


\section{Mapa 2: Demonstração geográfica dos pedidos de refúgio}

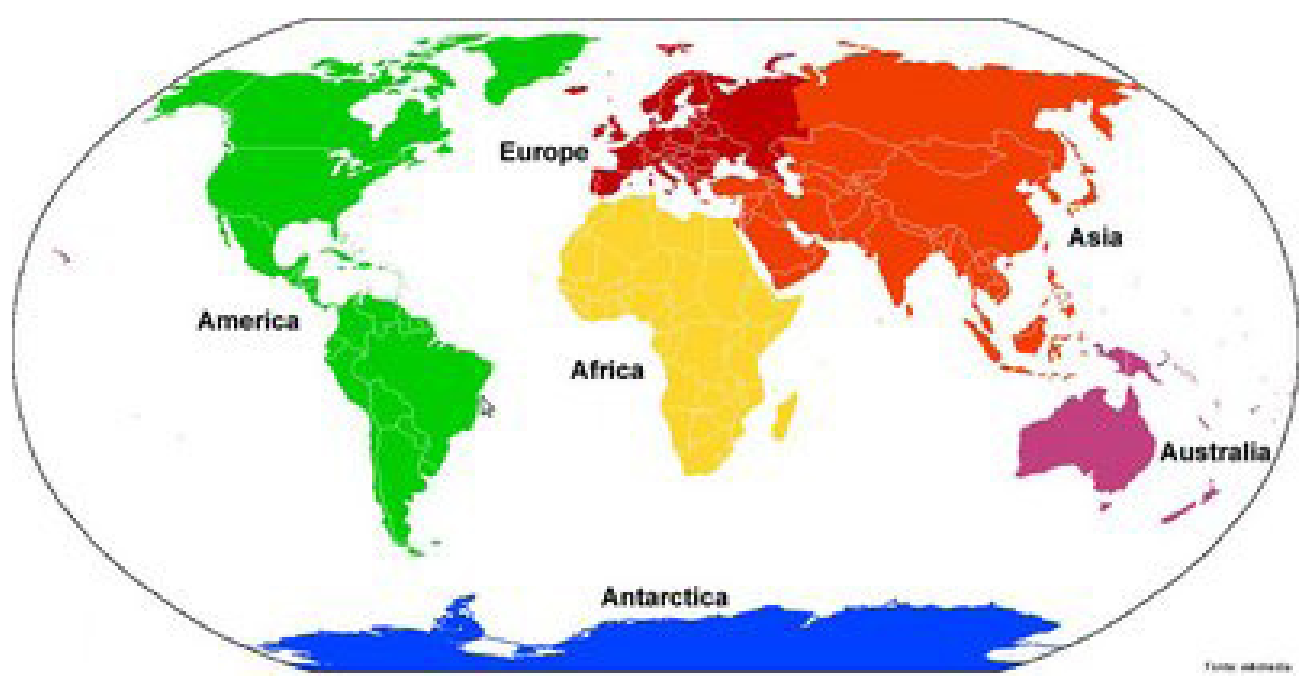

Os pedidos de refúgio foram exclusivamente apresentados por pessoas do sexo masculino, residentes majoritariamente no continente africano, que concentrou $70 \%$ dos pedidos. $\mathrm{O}$ continente europeu, americano e asiático requereu apenas um pedido cada.

\section{Distribuição por sexo, nacionalidade e faixa etária}

Neste tópico abordar-se-á a relação entre nacionalidade, sexo e faixa etária dos presos federais assistidos pela Defensoria Pública da União, com o objetivo de identificar as particularidades do público atendido, cujos fatores são utilizados como subsídio para uma assistência sociojurídica comprometida com a garantia de direitos, tanto no contexto macro, da atividade judicante, quanto na singularidade das situaçóes individuais.

\subsection{Brasileiros e Estrangeiros}

Do total de 135 presos federais assistidos pelo Núcleo Criminal da Defensoria Pública da Uniáo no Rio de Janeiro, entre outubro de 2015 a setembro de 2017, 115 são presos federais do sexo masculino, dos quais 43 são estrangeiros; enquanto que 20 são presas do sexo feminino, das quais 8 são estrangeiras. A proporção entre os sexos e a nacionalidade pode ser visualizada pela Tabela 3 . 
Tabela 3: Divisáo dos presos assistidos pela DPU/RJ por sexo e nacionalidade

\begin{tabular}{|c|c|c|}
\hline \multicolumn{3}{|c|}{ Brasileiros X Estrangeiros } \\
\hline$*$ & Homens & Mulheres \\
\hline Brasileiros & 72 & 12 \\
\hline Estrangeiros & $43^{*}$ & 08 \\
\hline Total/Sexo & 115 & 20 \\
\hline
\end{tabular}

Obs.: * O estrangeiro apátrida foi inserido nesse campo.

Gráfico 3: Divisão dos presos assistidos pela DPU/RJ por sexo e nacionalidade

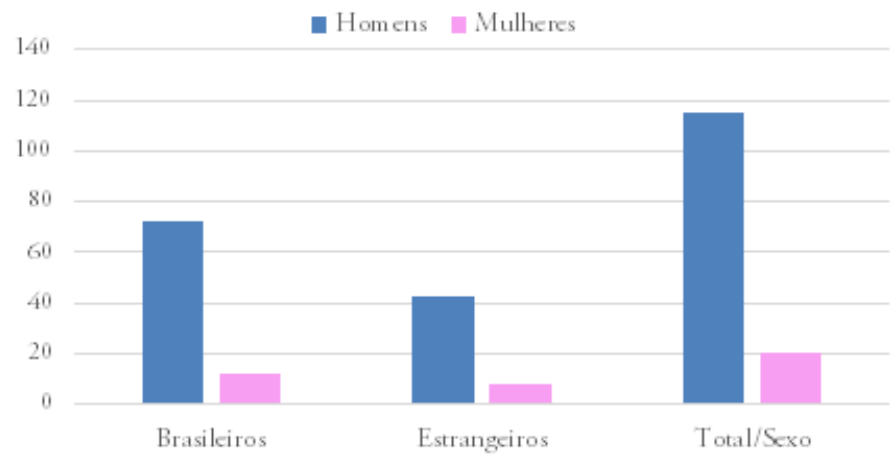

\subsection{Faixa Etária}

Com relação a divisão por faixa etária optou-se por trabalhar com apenas quatro faixas etárias, assim definidas: 18 a 25 - representando as pessoas que estão iniciando a vida adulta; 26 a 45 - faixa com maior concentração de adultos que compóem a parcela da população economicamente ativa; 46 a 59 - faixa das pessoas consideradas de meia-idade; e a faixa dos idosos com as pessoas com 60 anos ou mais. 
Tabela 4: Distribuição por faixa etária dos presos federais

\begin{tabular}{|c|c|}
\hline Idades: & Presos Federais \\
\hline 18 a 25 anos & 33 \\
\hline 26 a 45 anos & 63 \\
\hline 46 a 59 anos & 24 \\
\hline$\leq \mathrm{de} 60$ anos & 11 \\
\hline Náo declarado & 04 \\
\hline Total: & 135 \\
\hline
\end{tabular}

A análise dos dados indica que os presos federais se concentram na faixa etária de adultos, constituindo uma população potencialmente ativa para o mercado de trabalho.

É imperioso destacar o alto percentual, de aproximadamente $24 \%$, de presos jovens, ou seja, incluídos na faixa etária de 18 a 25 anos, que deveriam estar em processo de qualificação profissional para uma melhor inserção no mercado de trabalho, e que iniciam sua vida adulta como interno do sistema carcerário.

Outro aspecto que merece destaque é o percentual de aproximadamente de $8 \%$ de presos classificados como idosos, em consonância com o Estatuto do Idoso, perspectiva que apresenta peculiaridades para a execução da política setorial de proteção ao idoso no âmbito do sistema penitenciário do Estado.

\section{Gráfico 4: Faixa etária dos presos federais}

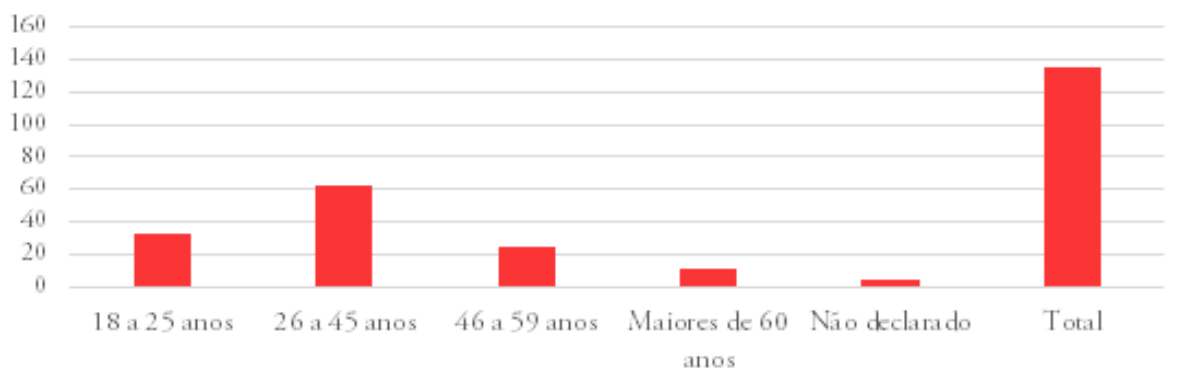




\subsubsection{Faixa Etária do Sexo Feminino}

O percentual de presas inseridas nas faixas etárias consideradas potencialmente ativas representam $90 \%$ do total de presas atendidas pela DPU, distribuídas em 18 a 25 anos - 35\%; 26 a 45 anos - 55\%; e 5\% nas faixas 46 a 59 e igual ou maior de 60 anos cada.

Tabela 5: Distribuição por faixa etária do sexo feminino

\begin{tabular}{|l|c|}
\hline Idades: & Presas Federais \\
\hline 18 a 25 anos & 07 \\
\hline 26 a 45 anos & 11 \\
\hline 46 a 59 anos & 01 \\
\hline < de 60 anos & 01 \\
\hline Total: & $\mathbf{2 0}$ \\
\hline
\end{tabular}

\section{Gráfico 5: Demonstração da faixa etária do sexo feminino}

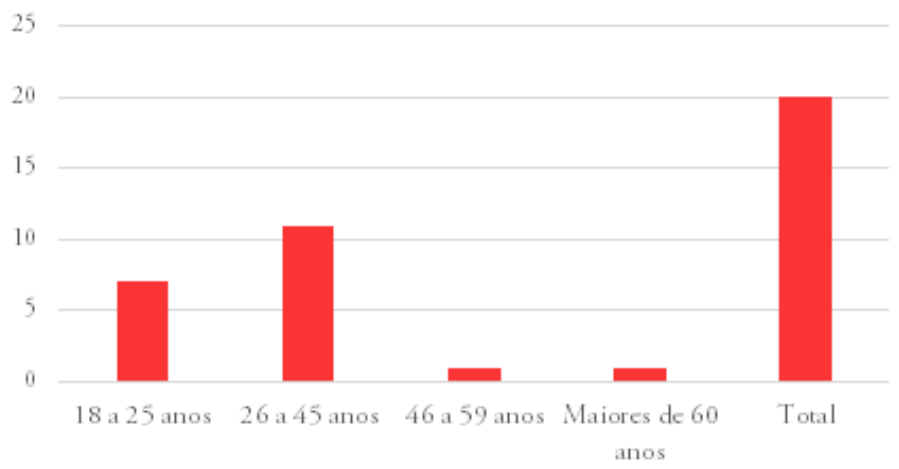

\subsubsection{Faixa etária do sexo feminino e a nacionalidade}

A abordagem analítica que distingue as presas brasileiras das estrangeiras, constatou que ambas as categorias se concentram na faixa etária entre 26 e 45 anos de idade, conforme os dados descritos na Tabela e Gráfico abaixo. 
Tabela 6: Distribuição por faixa etária e nacionalidade do sexo feminino

\begin{tabular}{|l|c|c|}
\hline Idades: & Brasileiras & Estrangeiras \\
\hline $\mathbf{1 8}$ a 25 anos & 3 & 4 \\
\hline 26 a 45 anos & 6 & 5 \\
\hline 46 a 59 anos & 1 & 0 \\
\hline$\leq 60$ anos & 1 & 0 \\
\hline Total: & $\mathbf{1 1}$ & $\mathbf{9}$ \\
\hline
\end{tabular}

Gráfico 6: Demonstração da faixa etária e nacionalidade do sexo feminino

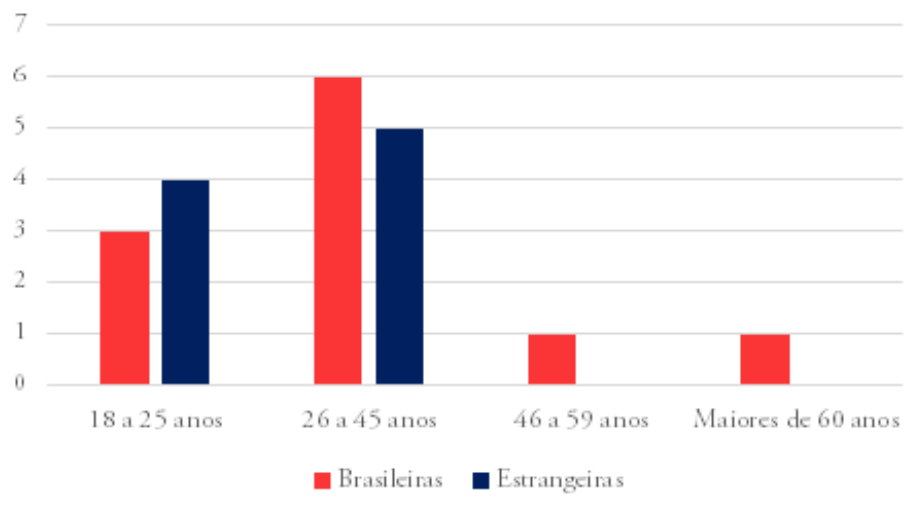

\subsubsection{Faixa Etária do Sexo masculino}

O percentual de presos inseridos nas faixas etárias consideradas potencialmente ativas representa aproximadamente $68 \%$ do total de presos atendidos pela DPU, distribuídos em 18 a 25 anos - $23 \%$; 26 a 45 anos - 45\%; 46 a 59-20\%; igual ou maior de 60 anos - 9\%; e os náo declarados representaram $3 \%$.

Em relação aos presos federais há a predominância da faixa etária de 26 a 45 anos de idade, conforme descrito na Tabela 7 e Gráfico 7. 
Tabela 7: Distribuição por faixa etária do sexo masculino

\begin{tabular}{|l|c|}
\hline Idades: & Presos Federais \\
\hline $\mathbf{1 8}$ a 25 anos & 26 \\
\hline $\mathbf{2 6}$ a $\mathbf{4 5}$ anos & 52 \\
\hline $\mathbf{4 6}$ a 59 anos & 23 \\
\hline $\mathbf{6} \mathbf{6 0}$ anos & 10 \\
\hline Não declarado & 4 \\
\hline Total: & $\mathbf{1 1 5}$ \\
\hline
\end{tabular}

Gráfico 7: Demonstração da faixa etária do sexo masculino

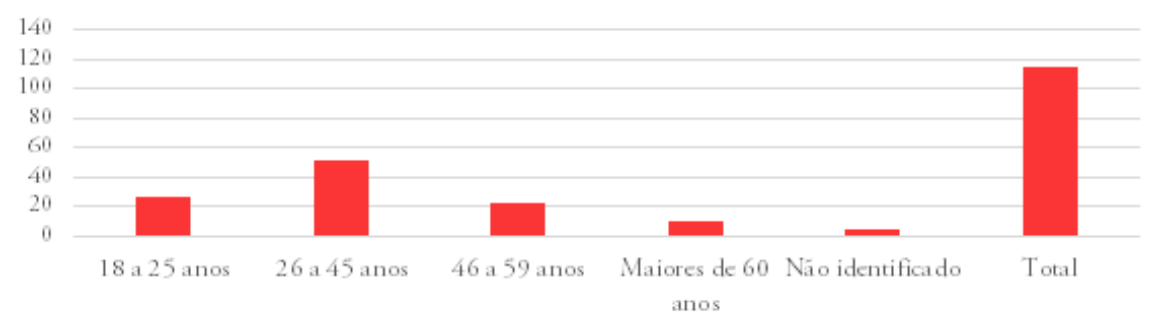




\subsubsection{Faixa etária do sexo masculino e a nacionalidade}

Também em relação aos presos do sexo masculino, foi realizada a análise dos dados comparando as faixas etárias e a nacionalidade, verificando-se a permanência do predomínio da faixa etária de 26 e 45 anos de idade, tanto entre brasileiros quanto em relação aos estrangeiros, conforme Tabela 8 e Gráfico 8 abaixo.

Tabela 8: Distribuiçáo por faixa etária e nacionalidade do sexo masculino

\begin{tabular}{|c|c|c|}
\hline Idades: & Brasileiros & Estrangeiros \\
\hline 18 a 25 anos & 21 & 5 \\
\hline 26 a 45 anos & 33 & 19 \\
\hline 46 a 59 anos & 9 & 14 \\
\hline$\leq 60$ anos & 7 & 3 \\
\hline Náo declarado & 2 & 2 \\
\hline Total: & 72 & 43 \\
\hline
\end{tabular}

Gráfico 8: Demonstraçáo da faixa etária e nacionalidade do sexo masculino

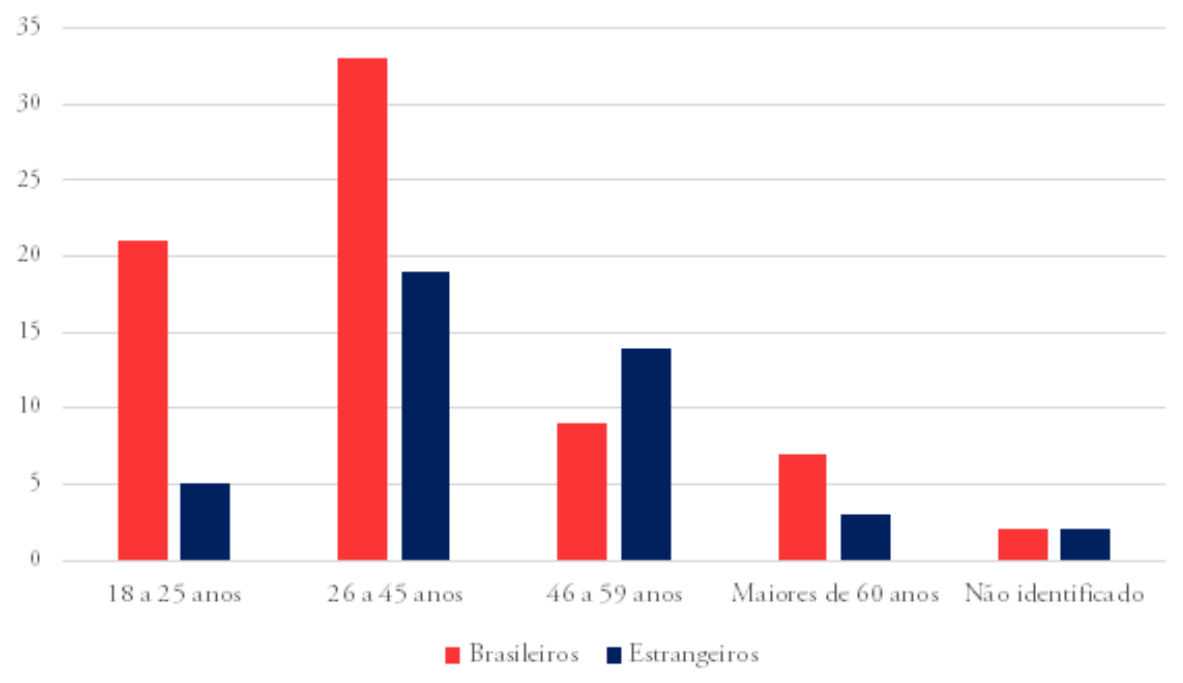


Observa-se a partir do exame dos dados coletados, que há entre os presos do sexo masculino, sejam brasileiros ou estrangeiros, forte predominância da faixa etária que abarca a parcela da populaçáo economicamente ativa, isto é, aquela localizada entre os 26 e 45 anos de idade, situação que se repete entre as presas federais.

\subsection{Estado Civil}

Do universo pesquisado constatou-se que $51 \%$ dos presos federais, entre homens e mulheres, são solteiros, $17 \%$ são casados, $16 \%$ constituíram união estável, $1 \%$ são viúvos, $1 \%$ estabeleceu união homoafetiva, $5 \%$ são divorciados, $1 \%$ é separado e $9 \%$ não declararam seu estado civil, conforme ilustrado no gráfico 9 .

\section{Gráfico 9: Demonstraçáo do estado civil dos presos federais}

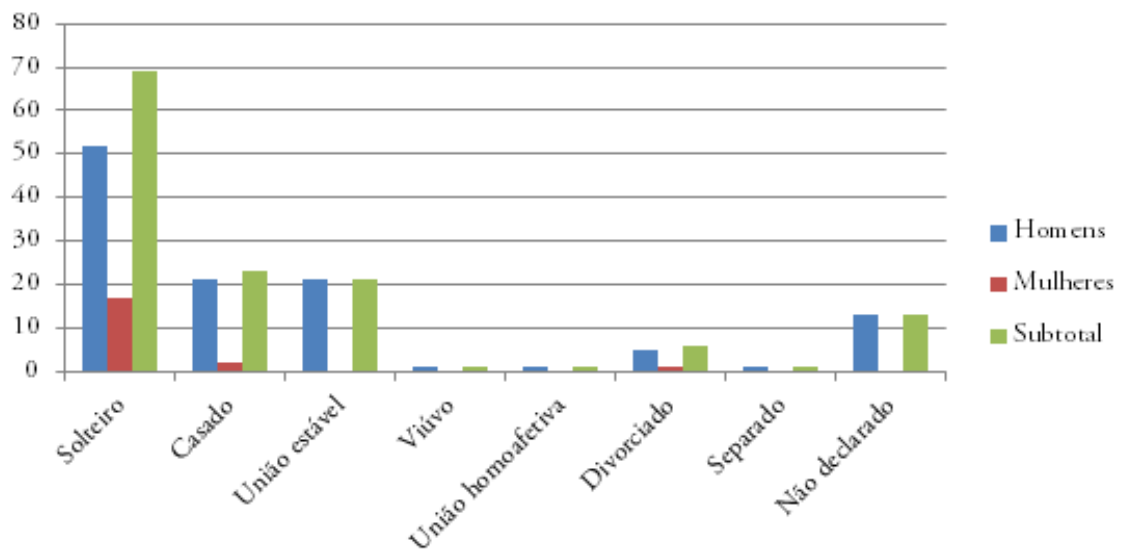

\subsection{Prole}

Entre os presos federais, considerando os homens e as mulheres, constatou-se que $31 \%$ não possuem filhos; $19 \%$ têm apenas 1 filho; $11 \%$ conceberam dois filhos; $16 \%$ apresentam 3 filhos ou mais; e 23\% não declararam tal informação. 


\section{Gráfico 10: Demonstraçáo do quantitativo de prole}

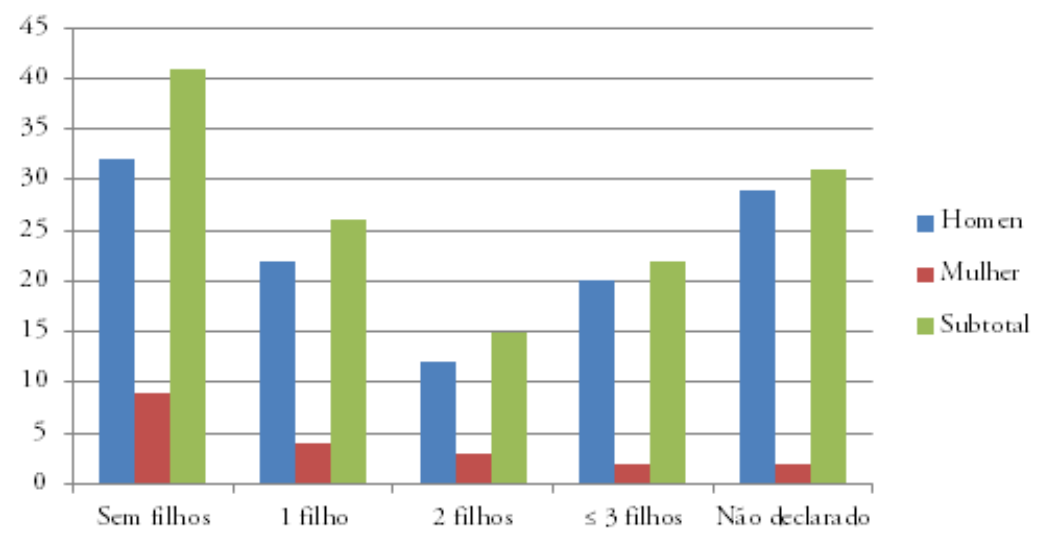

\section{Escolaridade}

Nesse tópico analisamos o grau de escolaridade dos presos federais, considerando homens e mulheres, e verificou-se que 19\% não concluíram o ensino fundamental; 7\% são concluintes do ensino fundamental; $12 \%$ não conseguiram terminar o ensino médio; $25 \%$ completaram o ensino médio; $10 \%$ ingressaram no ensino superior, mas não finalizaram o curso; 7\% possuem nível superior; 1\% é pós-graduado; e 19\% não declaram essa informação.

\section{Gráfico 11: Demonstração da escolaridade dos presos federais}

Legenda:

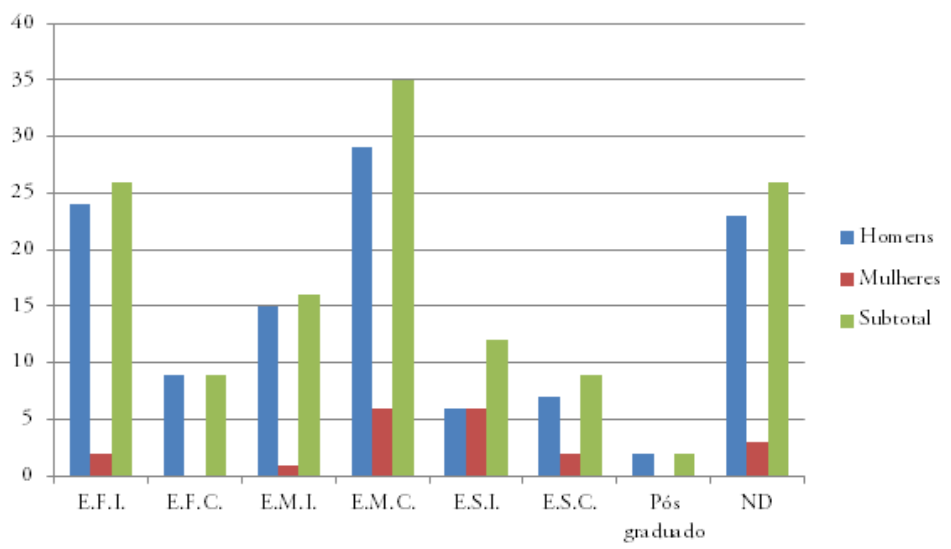

E.F.I. - Ensino Fundamental Incompleto; E.F.C. - Ensino Fundamental Completo; E.M.I. - Ensino Médio Incompleto; E.M.C. - Ensino Médio Completo; E.S.I. - Ensino Superior Incompleto; E.S.C. - Ensino Superior Completo; N.D. - Não declarado. 


\subsection{Relaçáo escolaridade e faixa etária}

Esse item objetiva relacionar a escolaridade com a faixa etária, para identificar as fragilidades da política de educação nacional, assim como construir subsídios passíveis de serem utilizados no Plano Estratégico de Educaçáo no âmbito do Sistema Prisional, sob a responsabilidade da Secretaria Estadual de Educação do Rio de Janeiro.

\section{Gráfico 12: Demonstração da escolaridade por faixa etária dos presos federais}

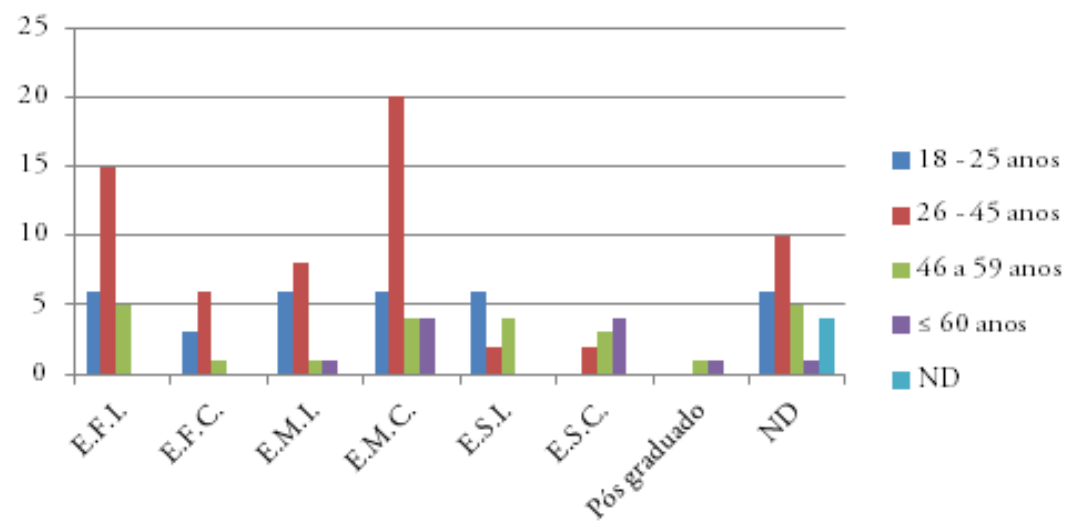

A análise dos dados demonstrou dentro dos $19 \%$ que não concluíram o ensino fundamental, que $4 \%$ encontra-se na faixa etária de 18 a 25 anos, $11 \%$ entre 26 a 45 anos e $4 \%$ entre 46 a 59 anos.

Já com relação aos $7 \%$ dos concluintes do ensino fundamental, $2 \%$ situam-se na faixa etária entre 18 a 25 anos, $4 \%$ entre 26 a 45 anos, e $1 \%$ entre 46 a 59 anos.

No que se refere aos $12 \%$ que náo terminaram o ensino médio, $4 \%$ estáo inseridos na faixa etária de 18 a 25 anos, 6\% na faixa de 26 a 45 anos, $1 \%$ entre 46 a 59 anos e $1 \%$ entre 60 anos ou mais.

Quanto aos 25\% dos presos federais que finalizaram o ensino médio, 5\% pertencem a faixa etária de 18 a 25 anos, $15 \%$ à de 26 a 45 anos, 3\% situa-se entre 46 a 59 anos e 3\% está na faixa dos de 60 anos ou mais.

No que tange aos $10 \%$ que iniciaram o curso superior, mas não conseguiram completar o curso, $4 \%$ encontram-se entre 18 a 25 anos, $2 \%$ entre 26 a 45 anos e $3 \%$ entre 46 a 59 anos.

Em relação aos 7\% graduados, 2\% pertencem a faixa etária de 26 a 45 anos, 2\% à de 46 a 59 anos e 3\% situam-se na faixa de 60 anos ou mais. 
Cabe ressaltar que entre os presos federais da faixa etária de 18 a 26 anos não existem concluintes de curso superior.

No que concerne aos pós-graduados, somente $1 \%$ do total dos presos federais alcançaram tal qualificação, sendo 1 da faixa de 46 a 59 anos e outro na de 60 anos ou mais.

Nesse tópico temos um percentual de $19 \%$ de entrevistados que não declararam sua escolaridade, sendo $4 \%$ da faixa etária de 18 a 25 anos, $7 \%$ pertencente a faixa de 26 a 45 anos, $4 \%$ referentes a faixa de 46 a 59 anos, $1 \%$ na faixa de 60 anos ou mais e 3\% que não declarou nem a faixa etária nem a escolaridade.

\subsubsection{Relação escolaridade e faixa etária no sexo masculino}

Nesse item desagregaram-se os dados relativos à faixa etária e escolaridade do sexo masculino dos assistidos da DPU/RJ, constatando-se que dos 18\% que náo concluíram o ensino fundamental, $4 \%$ encontram-se na faixa etária de 18 a 25 anos, $10 \%$ pertencem a faixa de 26 a 45 anos, $4 \%$ estão na de 46 a 59 anos.

Com relação aos $7 \%$ dos concluintes do ensino fundamental tem-se que $2 \%$ estão na faixa etária de 18 a 25 anos, 4\% estão inseridos na faixa de 26 a 45 anos, e $1 \%$ na faixa de 46 a 59 anos.

No que se refere aos $11 \%$ do ensino médio incompleto, $4 \%$ estão na faixa etária de 18 a 25 anos, $5 \%$ na de 26 a 45 anos, $1 \%$ na faixa de 46 a 59 anos, e $1 \%$ na de 60 anos ou mais.

No concernente aos $21 \%$ com o ensino médio completo, $4 \%$ encontram-se na faixa de 18 a 25 anos, $12 \%$ na faixa de 26 a 45 anos, 3\% referem-se a faixa de 46 a 59 anos, e $2 \%$ na faixa de 60 anos ou mais.

Quanto aos 4\% dos que não conseguiram completar sua graduação, $1 \%$ se encontra na faixa etária de 18 a 25 anos, $1 \%$ na de 26 a 45 anos, 2\% na faixa de 46 a 59 anos.

Já com relação aos $5 \%$ dos concluintes do ensino superior, $2 \%$ se encontram na faixa de 46 a 59 anos e $3 \%$ na faixa de 60 anos ou mais.

No que tange ao $1 \%$ dos pós graduados tem-se que $0,5 \%$ estão inseridos na faixa etária de 46 a 59 anos e os outros $0,5 \%$ pertencem a faixa de 60 anos ou mais.

Nesse tópico temos um percentual de $17 \%$ de pessoas que não declararam sua escolaridade, sendo 3\% da faixa etária de 18 a 25 anos, 7\% pertencente a faixa de 26 a 45 anos, 3\% referentes a faixa de 46 a 59 anos, $1 \%$ na faixa de 60 anos ou mais e 3\% que não declarou nem a faixa etária nem a escolaridade. 


\section{Gráfico 13: Demonstração da escolaridade por faixa etária do sexo masculino}

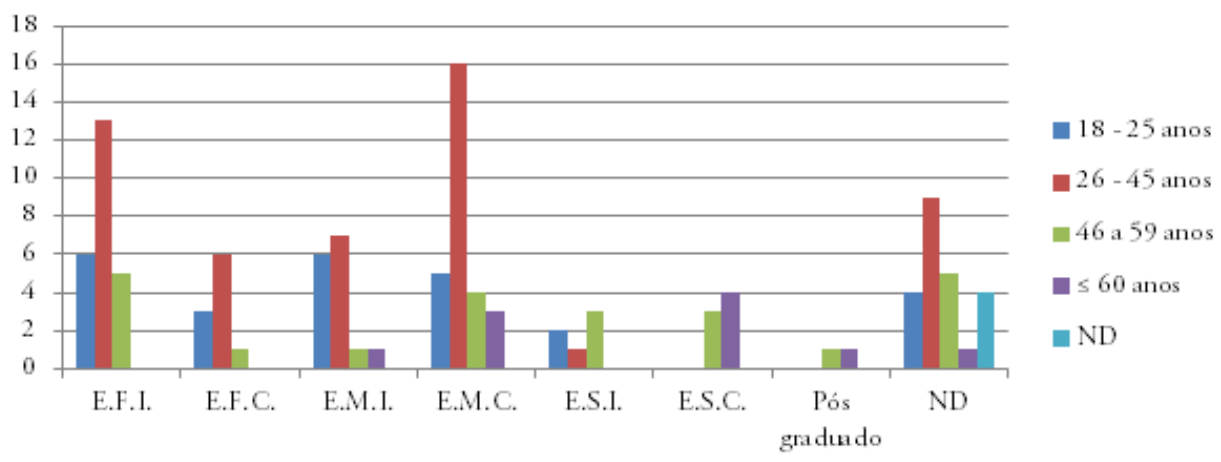

\subsubsection{Relação escolaridade e faixa etária no sexo feminino}

Nesse tópico se decompôs os dados relativos à faixa etária e escolaridade do sexo feminino dos assistidos da DPU/RJ, constatando-se que dos $1 \%$ que não terminaram o ensino fundamental pertencem a faixa de 26 a 45 anos.

No que se refere ao $1 \%$ do ensino médio incompleto todas estão inseridas na faixa etária de 26 a 45 anos.

No concernente aos $4 \%$ com o ensino médio completo, $1 \%$ encontram-se na faixa de 18 a 25 anos e 3\% na faixa de 26 a 45 anos.

Quanto aos 5\% das que não conseguiram completar sua graduação, 3\% se encontra na faixa etária de 18 a 25 anos, $0,7 \%$ na de 26 a 45 anos, $0,7 \%$ na faixa de 46 a 59 anos e $0,6 \%$ na faixa etária de 60 anos ou mais.

Já com relação aos $2 \%$ das concluintes do ensino superior todas pertencem a faixa etária de 26 a 45 anos.

Nesse tópico temos um percentual de $2 \%$ de pessoas que não declararam sua escolaridade, sendo $1,5 \%$ da faixa etária de 18 a 25 anos e $0,5 \%$ pertencente a faixa de 26 a 45 anos. 
Gráfico 14: Demonstraçáo da escolaridade por faixa etária do sexo feminino

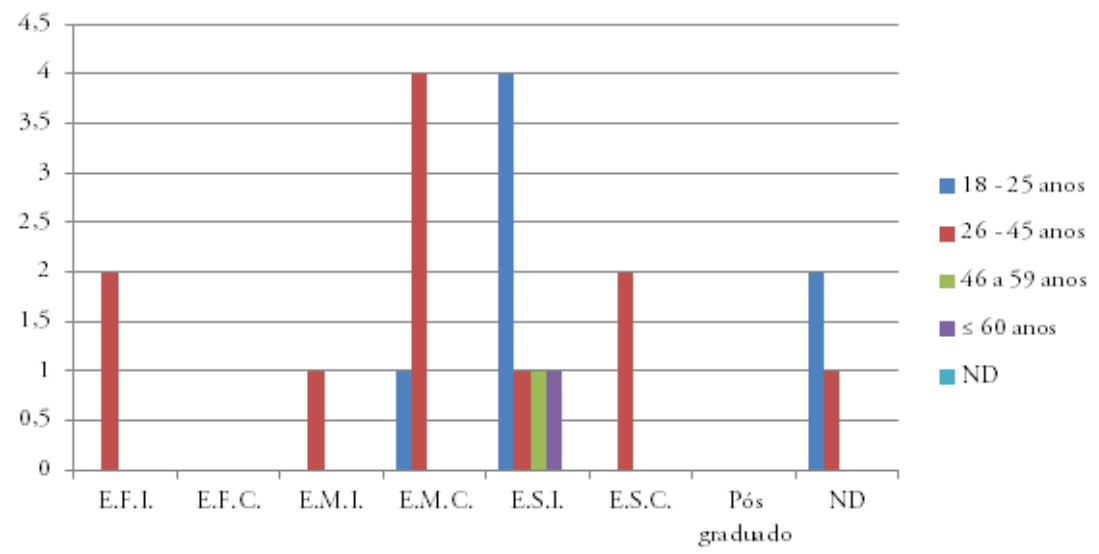

\section{Condiçáo de saúde}

Nesse tópico buscou-se, de forma incipiente, conhecer o perfil epidemiológico dos presos federais, e assim obter informações que viabilizem uma atuação institucional voltada para a garantia do direito à saúde desse segmento populacional.

Gráfico 15: Demonstraçáo da condiçáo de saúde dos presos federais

Doença crônica

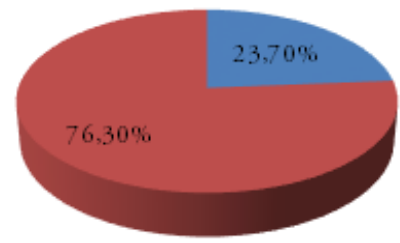

$$
\begin{aligned}
& \text { Apresentavam doença } \\
& \text { crônica quando da } \\
& \text { prisio } \\
& \text { Năo apresentavam } \\
& \text { doença crônica } \\
& \text { quando da prisio }
\end{aligned}
$$

A observação das informações revelou que $23,70 \%$ dos presos federais ingressaram no sis- 
tema penitenciário sendo portadores de doenças crônicas que demandam o uso contínuo de medicação e de acompanhamento médico periódico, para que não fiquem expostos ao agravamento da sua condição de saúde.

\subsection{Relaçáo entre a condiçáo de saúde e o sexo}

Existe uma variação na proporção de presos com diagnóstico de doenças crônicas, quando se efetua a desagregação dos dados por sexo. Enquanto $40 \%$ das detentas federais ingressam no sistema penitenciário já tendo conhecimento de serem portadoras de doenças crônicas, apenas $20,86 \%$ dos presos federais do sexo masculino relataram possuir algum agravo na sua condição de saúde.

\section{Gráfico 16: Demonstraçáo da condição de saúde e o sexo feminino}
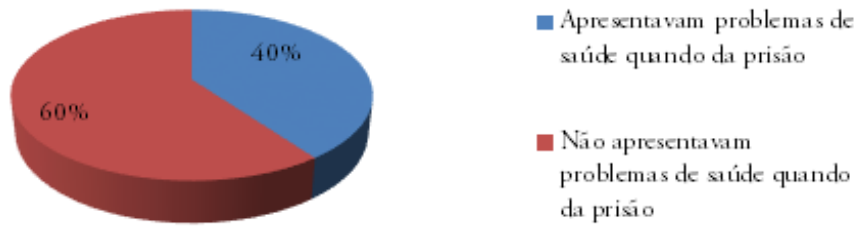

Gráfico 17: Demonstração da condição de saúde e o sexo masculino

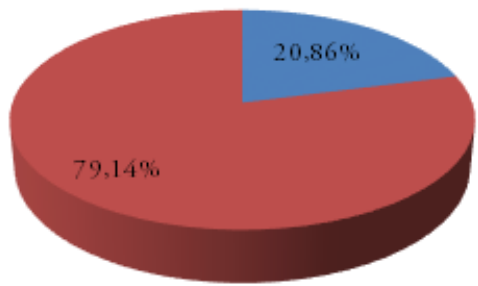

Apresentavam doença crônica quando da prisáo

- Năo apresentavam doença crônica quando da prisio 


\subsection{Quadro das doenças crônicas}

As principais doenças identificadas entre os presos federais foram as doenças hipertensivas, os transtornos mentais e comportamentais, as patologias do sistema osteomuscular e do estômago, para citar apenas algumas. Tais informaçóes são basilares para alimentar a Política Nacional de Atenção Integral à Saúde das Pessoas Privadas de Liberdade no Sistema Prisional

Convém ressaltar que se optou por não quantificar as doenças em porcentagem em razão de um mesmo interno possuir mais de uma patologia, esse fato comprometeria, para esse indicador, a utilização de tal metodologia.

Tabela 9: Quadro das doenças crônicas dos presos federais

\begin{tabular}{|l|c|}
\hline Doença Crônica & Quantidade \\
\hline Cegueira e visáo subnormal & 1 \\
\hline Diabetes & 2 \\
\hline Doenças do aparelho geniturinário & 3 \\
\hline Doenças do coração & 4 \\
\hline Doenças do Esôfago, do estômago e do duodeno & 5 \\
\hline Doenças do sistema nervoso & 3 \\
\hline Doenças do sistema osteomuscular e do tecido conjuntivo & 6 \\
\hline Doenças do sistema respiratório & 3 \\
\hline Doenças hipertensivas & 9 \\
\hline HIV & 3 \\
\hline Transtornos do ouvido & 1 \\
\hline Transtornos mentais e comportamentais & 7 \\
\hline
\end{tabular}

\section{Condição Laboral}

Nesse item abordar-se-á a questão da inserção no mercado de trabalho dos 135 presos federais, cujas informaçóes coletadas apontaram que 13\% estavam trabalhando com vínculo empregatício formal quando da sua prisão, 32\% eram trabalhadores da economia informal, 38\% estavam desempregados, 1\% é aposentado, e 16\% não declaram sua condição laboral. 


\section{Gráfico 18: Demonstraçáo da condiçáo laboral dos presos federais}

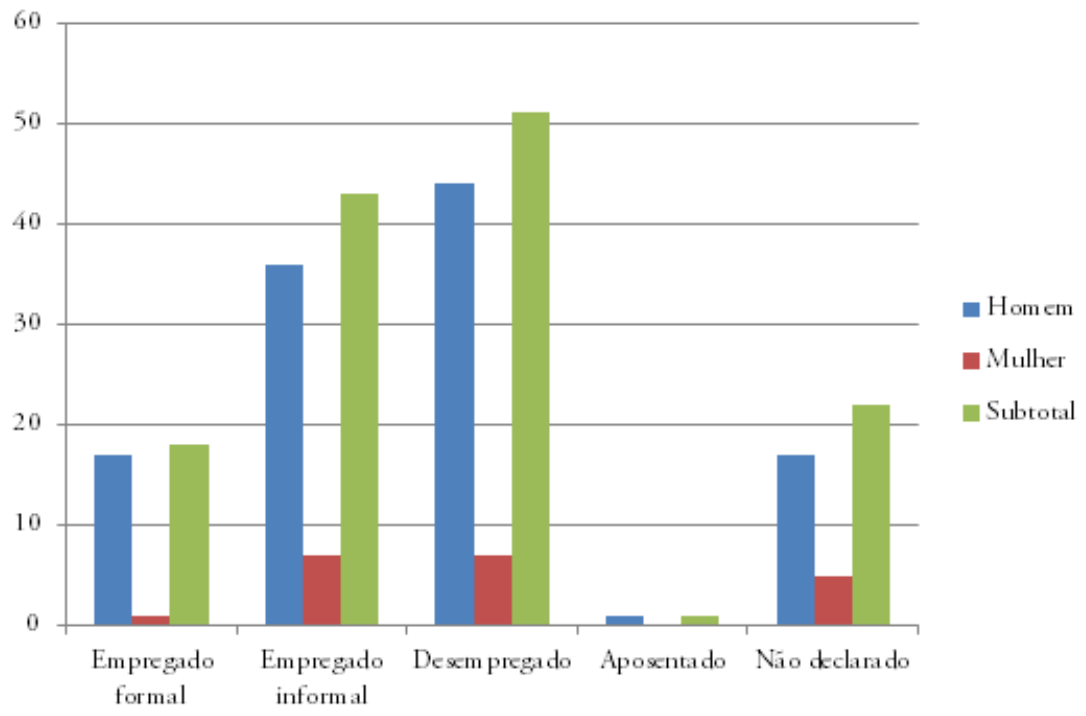

Desagregando os dados do gráfico 18, e considerando que o universo total das presas federais é de 20, tem-se que: $5 \%$ estavam com vínculo formal de trabalho, $35 \%$ estavam inseridas no mercado informal, $35 \%$ encontravam-se desempregadas e $25 \%$ não declarou sua condição laboral.

Com relação aos presos federais, cujo o universo pesquisado é de 115 pessoas, constatouse que: $15 \%$ eram empregados formais, $31 \%$ estavam inseridos no mercado informal de trabalho, $38 \%$ encontravam-se desempregados, $1 \%$ é aposentado e $15 \%$ não prestaram informações sobre a sua condição laboral.

Cabe destacar o percentual majoritário dos presos federais desempregados ou inseridos de forma marginal no mercado de trabalho quando da sua prisão.

\section{Processo Judicial}

Nesse item apresentar-se-á a incidência da tipificação penal na prática delitiva dos presos federais e as sentenças arbitradas pela Justiça Federal Criminal. 


\subsection{Tipificação}

Verificou-se com relação à tipificação penal imputada aos presos federais assistidos pela Defensoria Pública da União que $42 \%$ foram acusados pela prática do delito de tráfico de drogas, sendo esse o delito predominante em ambos os sexos; $5 \%$ pelo crime de documento falso; $7 \%$ pelo delito de estelionato; $4 \%$ pelo crime de moeda falsa; $27 \%$ pelo crime de roubo e furto; $2 \%$ pelo delito de tráfico de armas e munição; $7 \%$ devido a processos de extradição; e $6 \%$ foram enquadrados na categoria outros crimes.

Na categoria "Outros" estão inclusos os crimes com a tipificação penal de: peculato, extorsão mediante sequestro, lesão corporal, desacato e crimes contra administração pública.

É imperioso destacar que as práticas dos crimes de documento falso, roubo e furto foram executados somente por pessoas do sexo masculino, assim como as pessoas que se encontram em situação de privação de liberdade aguardando o julgamento dos processos de extradição também são exclusivamente do sexo masculino.

Tabela 10: Comparação entre a tipificaçáo penal imputada e o sexo do (a) preso (a)

\begin{tabular}{|l|c|c|c|}
\hline \multicolumn{4}{|c|}{ Relação quantitativa -Tipificação } \\
\hline Crimes: & Presos: & Homens: & Mulheres: \\
\hline Tráfico Internacional de Drogas & 57 & 41 & 16 \\
\hline Documento Falso & 7 & 7 & 0 \\
\hline Estelionato & 9 & 8 & 1 \\
\hline Moeda Falsa & 6 & 5 & 1 \\
\hline Roubo e Furto & 36 & 36 & 0 \\
\hline Tráfico de Armas e Munição & 3 & 2 & 1 \\
\hline Extradição & 9 & 9 & 0 \\
\hline Outros* & 8 & 7 & 1 \\
\hline Total: & 135 & 115 & 20 \\
\hline
\end{tabular}


Gráfico 19: Comparação entre a tipificação penal imputada e o sexo do (a) preso (a)

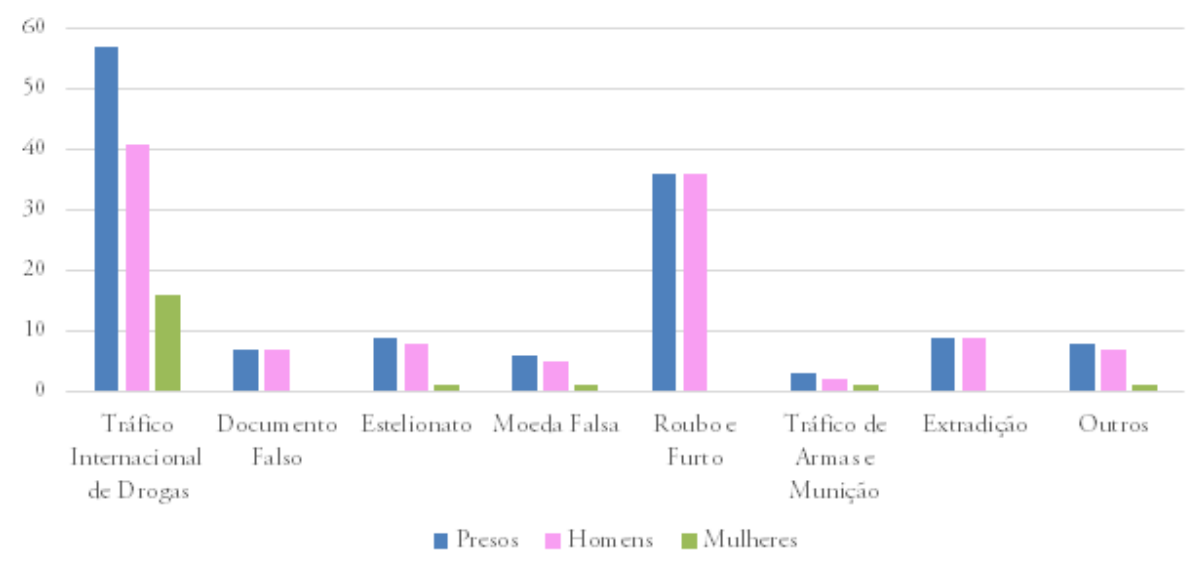

\subsection{Tipificaçáo, Sexo e Faixa Etária}

Nesse tópico procurou-se relacionar a tipificação penal com o sexo e a faixa etária, na perspectiva de observar a influência desses fatores na prática delitiva.

\subsubsection{Sexo Feminino}

Ainda na análise da tipificação penal, foi incluído, além de dados relativos ao sexo do (a) preso (a) assistido (a) pela Defensoria Pública da Uniáo, informaçóes acerca da faixa etária dessas pessoas, podendo-se observar, pela Tabela 11 e Gráfico 20, o predomínio da imputação por tráfico de drogas em relação a metade das faixas etárias das presas do sexo feminino, com exceção daquelas com idade entre 46 e 59 e acima de 60 anos. 
Tabela 11: Análise da tipificação penal, sexo feminino e faixa etária

\begin{tabular}{|l|c|c|c|c|}
\hline & $\mathbf{1 8}$ a 25 anos & $\mathbf{2 6}$ a 45 anos & $\mathbf{4 6}$ a 59 anos & $\geq \mathbf{6 0}$ anos \\
\hline $\begin{array}{l}\text { Tráfico Internacional de } \\
\text { Drogas }\end{array}$ & 7 & 9 & 0 & 0 \\
\hline Estelionato & 0 & 0 & 0 & 1 \\
\hline Moeda Falsa & 0 & 1 & 0 & 0 \\
\hline Tráfico de armas e muniçáo & 0 & 1 & 0 & 0 \\
\hline Outros - Peculato & 0 & 0 & 1 & 0 \\
\hline
\end{tabular}

\section{Gráfico 20: Análise da tipificação penal, sexo feminino e faixa etária}

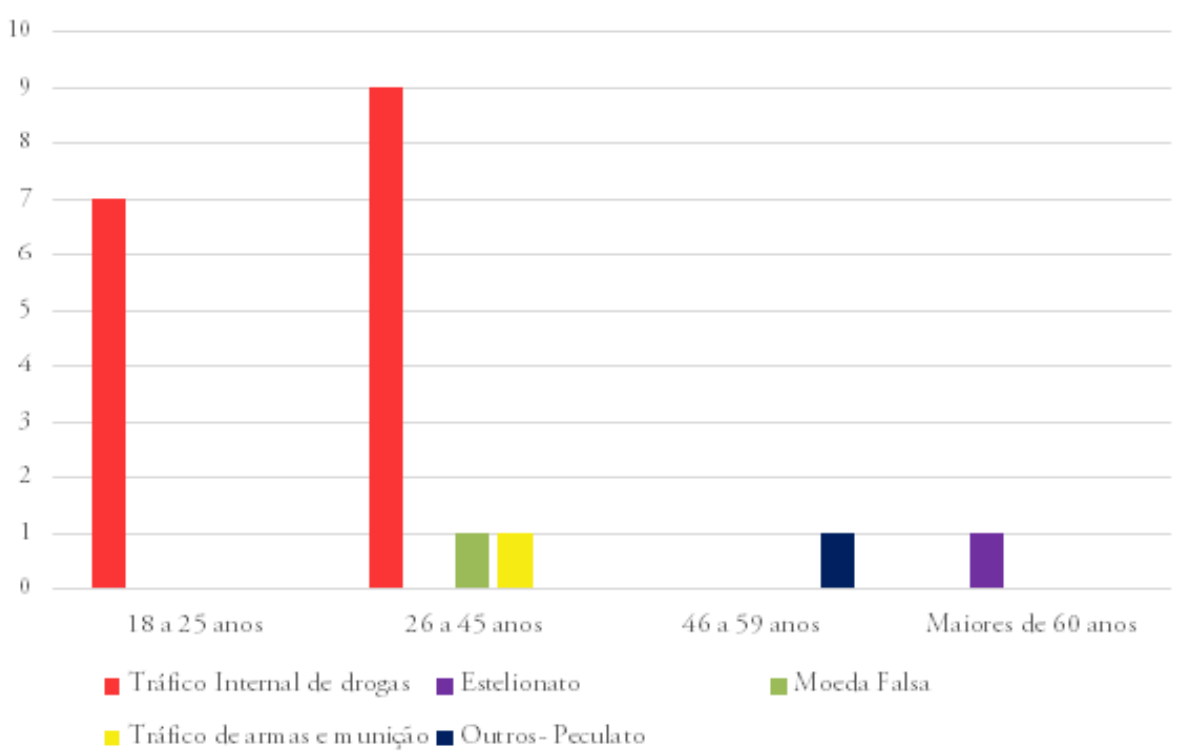

A observação dos dados da tabela 11 e do gráfico 20 demonstram que do universo das 20 presas federais, $80 \%$ foram presas pela prática do crime de tráfico de drogas, e pertencem as faixas etárias de 18 a 25 anos e de 26 a 45 anos.

Os 20\% restantes das presas federais foram denunciadas da seguinte forma: $5 \%$ por estelionato, encontrando-se na faixa etária de 60 anos ou mais; $5 \%$ por moeda falsa, pertencendo a faixa de 26 a 45 anos; 5\% por tráfico de armas e munição, estando na faixa dos 26 a 45 anos; e $5 \%$ por peculato, sendo da faixa de 46 a 59 anos.

Os dados indicam que os crimes praticados por pessoas do sexo feminino, no que se refere aos delitos federais, são aqueles que não oferecem maior risco de confrontos com terceiros. 


\subsubsection{Sexo Masculino}

No tocante aos presos do sexo masculino, mantém-se o predomínio do crime de tráfico internacional de drogas, principalmente nas faixas etárias compreendidas entre 18 e 25 anos, bem como de 26 a 45 anos, conforme demonstrado na tabela 12 e no Gráfico 21 .

Tabela 12: Análise da tipificaçáo penal, sexo masculino e faixa etária

\begin{tabular}{|l|c|c|c|c|c|}
\hline & $\begin{array}{l}\mathbf{1 8} \text { a } 25 \\
\text { anos }\end{array}$ & $\begin{array}{l}\mathbf{2 6} \text { a } 45 \\
\text { anos }\end{array}$ & $\begin{array}{l}\mathbf{4 6} \text { a 59 } \\
\text { anos }\end{array}$ & $\begin{array}{l}\mathbf{2 6 0} \\
\text { anos }\end{array}$ & Náo declarado \\
\hline $\begin{array}{l}\text { Tráfico internacional } \\
\text { de drogas }\end{array}$ & 10 & 18 & 7 & 5 & 1 \\
\hline $\begin{array}{l}\text { Tráfico de armas e } \\
\text { muniçáo }\end{array}$ & 1 & 1 & 0 & 0 & 0 \\
\hline Documento Falso & 1 & 6 & 1 & 0 & 0 \\
\hline Estelionato & 0 & 1 & 5 & 2 & 1 \\
\hline Moeda Falsa & 2 & 3 & 0 & 0 & 0 \\
\hline Roubo e Furto & 12 & 20 & 3 & 0 & 1 \\
\hline Extradiçáa & 0 & 2 & 5 & 1 & 1 \\
\hline Outros & 0 & 1 & 2 & 2 & 0 \\
\hline
\end{tabular}

Gráfico 21: Análise da tipificação penal, sexo masculino e faixa etária

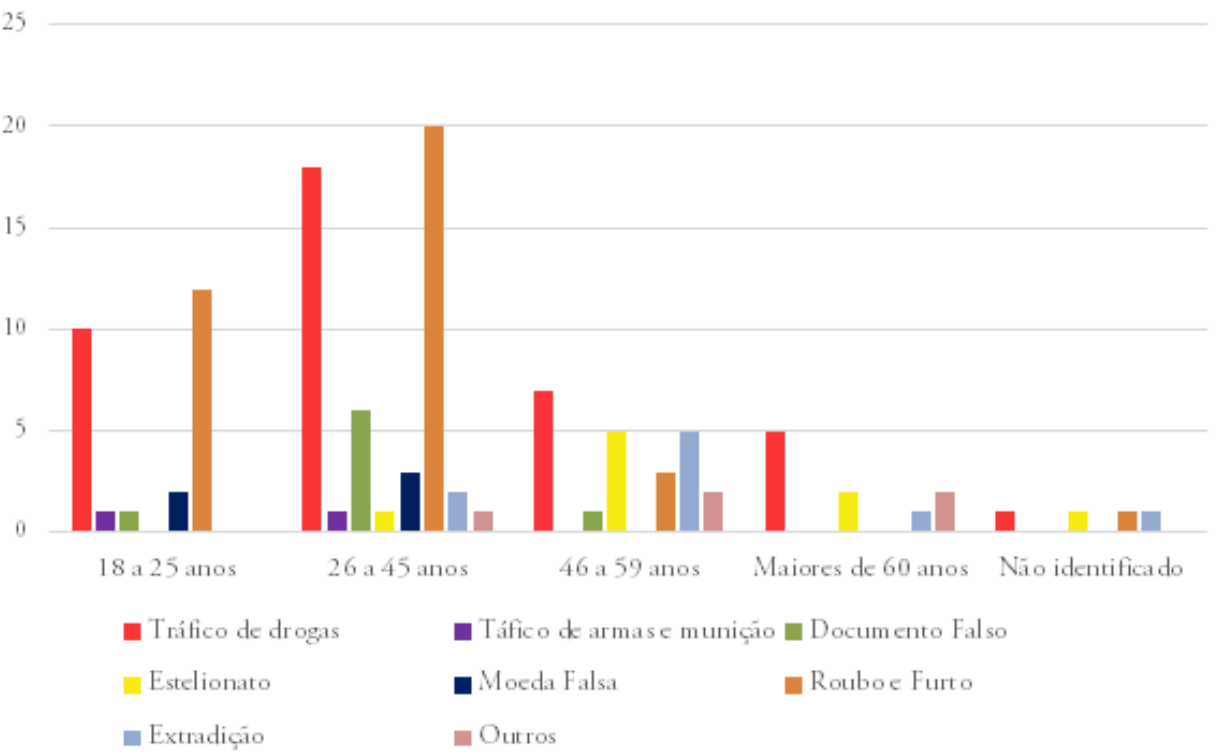


O exame dos dados indica que do universo dos 115 presos federais, $36 \%$ foram presos pela prática do crime de tráfico de drogas.

Com relação ao tráfico de armas a incidência foi de $2 \%$, sendo $1 \%$ entre a faixa 18 a 25 anos e $1 \% 26$ a 45 anos.

No que se refere aos $7 \%$ que praticaram o crime de documento falso, $1 \%$ pertenciam a faixa etária de 18 a 25 anos, $5 \%$ à de 26 a 45 anos e $1 \%$ encontram-se na faixa de 46 a 59 anos.

Quanto aos $8 \%$ que realizaram o delito de estelionato, $1 \%$ encontram-se na faixa de 26 a 45 anos, $4 \%$ pertencem a faixa de 46 a 59 anos, $2 \%$ à de 60 anos ou mais e $1 \%$ náo declaram informaçôes sobre sua idade.

No que tange aos $4 \%$ que são acusados pelo crime de moeda falsa, $1,5 \%$ pertencem a faixa de 18 a 25 anos e $2,5 \%$ a faixa de 26 a 45 anos.

Já com relação aos $31 \%$ que foram denunciados pelos delitos de roubo e furto, $10 \%$ estão inseridos na faixa etária de 18 a 25 anos, $17 \%$ pertencem a faixa etária de 26 a 45 anos, $3 \%$ entre 46 a 59 anos e $1 \%$ não declararam sua data de nascimento.

Os casos de extradiçáo somam $8 \%$, onde $2 \%$ pertencem a faixa etária de 26 a 45 anos, $4 \%$ encontram-se na faixa de 46 a 59 anos, $1 \%$ entre a faixa de 60 anos ou mais, e $1 \%$ não informaram sua idade.

No concernente aos $4 \%$ que praticaram os crimes categorizados nesse estudo como outros, $1 \%$ encontram-se na faixa de 26 a 45 anos, $1,5 \%$ na faixa de 46 a 59 anos e $1,5 \%$ na faixa de 60 anos ou mais.

\subsection{Sentença}

Nesse item tratar-se-á da prolação da sentença pela Justiça Federal Criminal nos 135 processos em que as defesas foram patrocinadas pela DPU/RJ. 
Tabela 13: Análise da porcentagem das sentenças exaradas pela Justiça Federal Criminal

\begin{tabular}{|l|c|c|c|}
\hline & Homens & Mulheres & Total \\
\hline Presos sem sentença & 14 & 1 & 15 \\
\hline Restritiva de Direitos & 19 & 7 & 26 \\
\hline Regime Aberto & 10 & 4 & 14 \\
\hline Regime Semi- Aberto & 26 & 3 & 29 \\
\hline Regime fechado & 30 & 5 & 35 \\
\hline Absolvido & 9 & 0 & 9 \\
\hline Extraditado & 4 & 0 & 4 \\
\hline Medidas cautelares* & 3 & 0 & 3 \\
\hline
\end{tabular}

*Assistidos em liberdade provisória enquanto aguardam sentença no processo judicial.

Gráfico 22: Análise da porcentagem das sentenças exaradas pela Justiça Federal Criminal

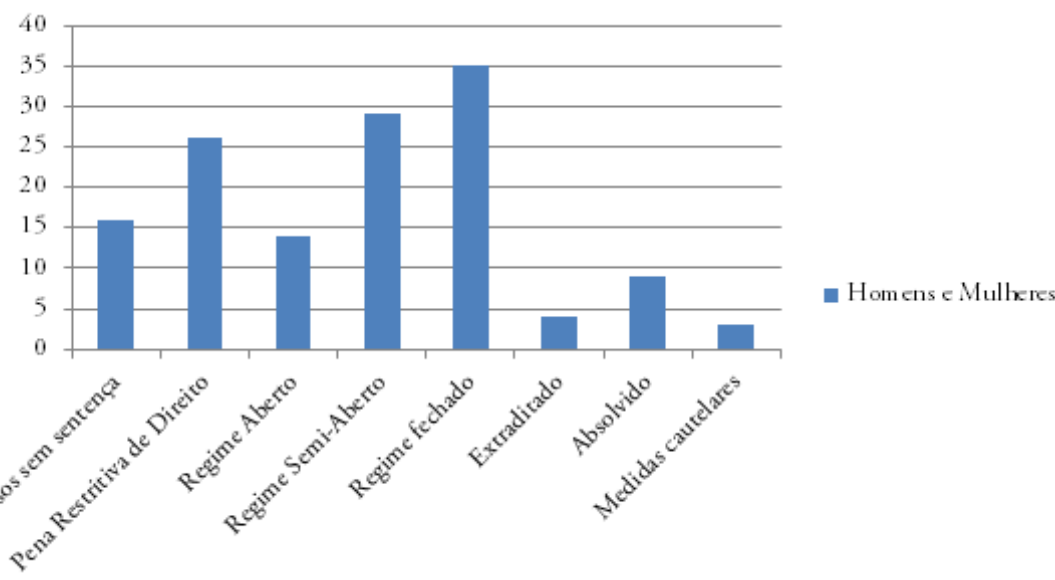

O estudo da tabela 13 e do gráfico 22 demonstra que dos 135 presos federais, considerando homens e mulheres, $12 \%$ estavam sem sentença, quando do fechamento dessa pesquisa, em 30/09/2017.

Dos sentenciados $19 \%$ receberam a pena restritiva de direitos, $10 \%$ foram sentenciados ao regime aberto, $21 \%$ ao regime semiaberto, $26 \%$ ao fechado, $7 \%$ foram absolvidos, $3 \%$ 
foram extraditados e $2 \%$ obtiveram medidas cautelares antes de ter sua sentença proferida.

Gráfico 23: Análise da porcentagem das sentenças exaradas pela Justiça Federal Criminal por sexo

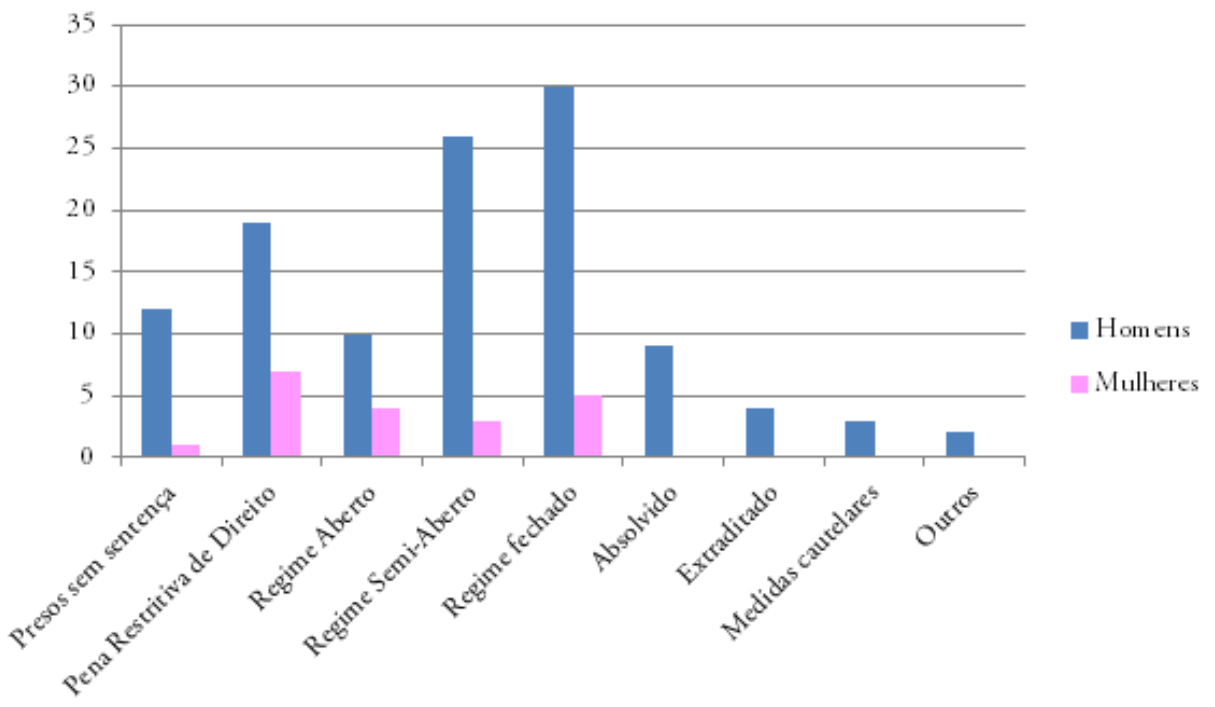

Ao decompor os dados das sentenças arbitradas pela Justiça Federal por sexo, observa-se que dos 115 presos federais do sexo masculino, $12 \%$ não haviam sido sentenciados até o fechamento desta pesquisa, $16 \%$ receberam a pena restritiva de direitos, $9 \%$ foram sentenciados ao regime aberto, $23 \%$ ao semiaberto, $26 \%$ ao fechado, $8 \%$ foram absolvidos, $3 \%$ tiveram o pedido de extradição deferido pelo Superior Tribunal Federal e 3\% receberam medidas cautelares enquanto aguardavam sua sentença.

Com relação às 20 mulheres assistidas pela DPU/RJ, 5\% não havia recebido sentença até a conclusão desse estudo, $35 \%$ foram sentenciadas com a pena restritiva de direitos, $20 \%$ receberam o regime inicial de cumprimento da pena o aberto, $15 \%$ o semiaberto e $25 \%$ o fechado. Nenhuma mulher, no período pesquisado foi absolvida.

\section{CONSIDERAÇÓES FINAIS}

As informaçôes contidas no II Panorama dos Presos Federais assistidos pela DPU/RJ refirmaram que as pessoas em situação de privação de liberdade do sexo masculino continuam sendo em maior número do que as do sexo feminino; que os presos federais reproduzem 
a tendência nacional de serem jovens e com baixa escolaridade. Apesar da pesquisa não evidenciar, a análise bruta dos dados demonstrou que os presos federais que contam com maior grau de escolaridade são os estrangeiros.

Outra peculiaridade dos presos estrangeiros relaciona-se com o fato de alguns países não contarem com representação consular no Estado do Rio de Janeiro, perspectiva que compromete a manutençẫo e preservação dos vínculos familiares desse segmento. Situação agravada pela realidade do sistema prisional desse Estado, que não permite o contato telefônico entre os internos do sistema penitenciário e o mundo exterior. Nesses casos a única comunicação possível é a realizada por intermédio de missivas.

Quanto às informaçóes sobre a condição de saúde dos presos federais, apresentadas nesse documento, podem ser consideradas singulares, tendo em vista que nem o Infopen/2016, nem o Relatório de gestão: supervisão do departamento e fiscalização do sistema carcerário e do sistema de execução de medidas socioeducativas elaborado pelo Conselho Nacional de Justiça conseguiram tratar de tal temática no que se refere ao Estado do Rio de Janeiro.

A ausência de informações sobre a saúde dos presos produz reflexos na elaboração, execução e avaliação da política social de saúde, expondo a população carcerária do Estado a risco de agravos a sua condição de saúde.

Com relação a questão da situação laboral das pessoas entrevistadas quando do ingresso no sistema penitenciário, é notória a inserção marginal no mercado de trabalho vivenciada por esse segmento populacional. Realidade que tende a se perpetuar quando do término do cumprimento da pena de prisão, devido a insuficiência das políticas sociais de reinserção laboral direcionadas aos egressos do sistema.

No concernente a tipificação penal, essa segunda edição do Panorama do Preso federal, reafirmou que o crime de tráfico internacional de drogas continua sendo o delito predominante entre a população carcerária analisada.

Já a análise das sentenças aplicadas pela Justiça Federal Criminal demonstrou que as pessoas do sexo feminino que foram presas não receberam a absolvição. Mesmo tendo sido constatado que os crimes praticados por mulheres foram aqueles que não envolvem violência ou grave ameaça.

As informaçôes e análises apresentadas no II Panorama indicam o desafio das instituiçóes em promover uma maior interlocução com as Secretarias de Estado responsáveis pelas políticas públicas de saúde, educação e trabalho como estratégia basilar para a materialização dos direitos humanos no sistema penitenciário. 